\title{
Aripiprazole once-monthly for treatment of schizophrenia: double-blind, randomised, non-inferiority study*
}

W. Wolfgang Fleischhacker, Raymond Sanchez, Pamela P. Perry, Na Jin, Timothy Peters-Strickland, Brian R. Johnson, Ross A. Baker, Anna Eramo, Robert D. McQuade, William H. Carson, David Walling and John M. Kane

\section{Background}

Long-acting injectable formulations of antipsychotics are treatment alternatives to oral agents.

\section{Aims}

To assess the efficacy of aripiprazole once-monthly compared with oral aripiprazole for maintenance treatment of schizophrenia.

\section{Method}

A 38-week, double-blind, active-controlled, non-inferiority study; randomisation (2:2:1) to aripiprazole once-monthly $400 \mathrm{mg}$, oral aripiprazole (10-30 mg/day) or aripiprazole once-monthly $50 \mathrm{mg}$ (a dose below the therapeutic threshold for assay sensitivity). (Trial registration: clinicaltrials.gov, NCT00706654.)

\section{Results}

A total of 1118 patients were screened, and 662 responders to oral aripiprazole were randomised. Kaplan-Meier estimated impending relapse rates at week 26 were $7.12 \%$ for aripiprazole once-monthly $400 \mathrm{mg}$ and $7.76 \%$ for oral aripiprazole. This difference $(-0.64 \%, 95 \% \mathrm{Cl}-5.26$ to 3.99$)$ excluded the predefined non-inferiority margin of $11.5 \%$. Treatments were superior to aripiprazole once-monthly $50 \mathrm{mg}(21.80 \%, P \leqslant 0.001)$

\section{Conclusions}

Aripiprazole once-monthly $400 \mathrm{mg}$ was non-inferior to oral aripiprazole, and the reduction in Kaplan-Meier estimated impending relapse rate at week 26 was statistically significant $v$. aripiprazole once-monthly $50 \mathrm{mg}$.

\section{Declaration of interest}

W.W.F. has received research grants from Otsuka, Pfizer, Janssen and Reckitt-Benckiser as well as consulting honoraria from Lundbeck, Roche, Bristol-Myers Squibb, Otsuka, Janssen, Pfizer, MedAvante, Takeda, Endo and Vanda. He has received speaker honoraria from Lundbeck, Janssen, Otsuka and Takeda as well as holds stock from MedAvante. R.S., P.P., N.J., T.P.-S., B.R.J., R.A.B., R.D.M. and W.H.C. are employees of Otsuka Pharmaceutical Commercialization, Inc. (Tokyo, Japan). A.E. is an employee of Lundbeck LLC. D.W. has received research grants from Otsuka, Pfizer, Eli Lilly, Janssen, Targacept, Lundbeck, Sunovion, Merck, Alkermes, Bristol-Myers Squibb, Reckitt, Elan, Abbott and Amgen. J.M.K. has received honoraria for lectures and/or consulting from Alkermes, Amgen, Bristol-Myers Squibb, Cephalon, Eisai, Boehringer Ingelheim, Eli Lilly, Forrest, Genentech, Intracellular Therapeutics, Janssen, Johnson and Johnson, Lundbeck, Merck, Novartis, Otsuka, Pfizer, Pierre Fabre, Proteus, Reviva, Roche, Sunovion and Targacept. He is a shareholder of MedAvante.
Long-acting injectable (LAI) formulations of antipsychotics are valuable treatment alternatives to oral agents, offering continuous medication delivery and favourable dosing intervals. Evidence suggests that many patients accept and may even prefer LAI administration. ${ }^{1,2}$ Aripiprazole once-monthly is an LAI formulation of aripiprazole that is currently approved in the USA and Europe for the treatment of schizophrenia, and is the first dopamine partial agonist agent available in a long-acting formulation. Aripiprazole once-monthly is administered by gluteal injection and once injected, the active ingredient, aripiprazole, is slowly absorbed into the systemic circulation; there is no release vehicle or release-controlling membrane. In a previous study, aripiprazole once-monthly significantly delayed time to impending relapse compared with placebo. ${ }^{3}$ Aripiprazole, a dopamine partial

*Previously presented at the following conferences: 51st Annual Meeting of the American College of Neuropsychopharmacology (ACNP), 2-6 December 2012, Hollywood, Florida, USA; 14th International Congress on Schizophrenia Research (ICOSR), 21-25 April 2013, Orlando, Florida, USA; 166th Annual Meeting of the American Psychiatric Association (APA), 18-22 May 2013, San Francisco, California, USA; US Psychiatric and Mental Health Congress (USPMHC), 30 September-3 October 2013, Las Vegas, Nevada, USA; and Neuroscience Education Institute Psychopharmacology Congress (NEI), 14-17 November 2013, Colorado Springs, Colorado, USA. agonist, ${ }^{4}$ is an antipsychotic with well-established efficacy and safety over the short and long term. ${ }^{5}$ For LAI formulations, a study comparing the efficacy and safety $v$. the oral form is recommended to support authorisation by the European Medicines Agency (EMA) ${ }^{3}$ and to demonstrate efficacy, safety and tolerability similar to the established profile of the approved oral product. The objective of the present randomised, doubleblind, active-controlled, non-inferiority study was to assess the efficacy, safety, and tolerability of aripiprazole once-monthly $(400 \mathrm{mg})$ for the maintenance treatment of schizophrenia compared with oral aripiprazole and in comparison with a suboptimal dose of aripiprazole once-monthly $(50 \mathrm{mg})$. A suboptimal dose was included to confirm assay sensitivity (i.e. to demonstrate that the study was able to differentiate an effective treatment from a less effective or ineffective intervention by demonstrating superior efficacy).

\section{Method}

\section{Study design}

This was a 38-week, multicentre, randomised, double-blind, active-controlled study to evaluate the efficacy, safety and tolerability of an intramuscular depot formulation of aripiprazole (OPC-14597) as maintenance treatment in patients with 
schizophrenia (ASPIRE EU: Aripiprazole intramuscular depot program in schizophrenia, trial registration: clinicaltrials.gov, NCT00706654). The study consisted of a screening phase and three treatment phases (phases 1-3). Eligibility was determined during the screening phase (2-42 days). In treatment phase 1 (oral conversion phase, 4-6 weeks), patients were cross-titrated during weekly visits from other antipsychotic(s) to oral aripiprazole monotherapy to achieve a target dose of $10-15 \mathrm{mg} /$ day. Patients receiving oral aripiprazole monotherapy for schizophrenia at screening entered the study directly at phase 2 .

In phase 2 (oral stabilisation phase, $8-28$ weeks), patients were assessed fortnightly and stabilised on oral aripiprazole (10-30 mg/ day). Stability was defined as meeting the following criteria for 8 consecutive weeks: out-patient status; Positive and Negative Syndrome Scale (PANSS) ${ }^{6}$ total score $\leqslant 80$ and a score of $\leqslant 4$ (moderate) on each of the following items (possible scores of 1-7 for each item): conceptual disorganisation, suspiciousness, hallucinatory behaviour, and unusual thought content; Clinical Global Impression - Severity (CGI-S) score $\leqslant 4$ (moderately ill) $;^{7}$ and Clinical Global Impression - Severity of Suicidality (CGI-SS) score $\leqslant 2$ (mildly suicidal) on Part 1 and $\leqslant 5$ (minimally worsened) on Part 2 . The definition of stability was approved by the EMA and was similar to other stability definitions used in previous studies of approved LAIs for the treatment of schizophrenia. ${ }^{8}$

In phase 3 (double-blind maintenance phase for up to 38 weeks), eligible patients were randomised 2:2:1 to aripiprazole once-monthly $400 \mathrm{mg}$, oral aripiprazole $(10-30 \mathrm{mg} /$ day $)$ or aripiprazole once-monthly $50 \mathrm{mg}$. Aripiprazole once-monthly was administered into the gluteal muscle using a double-dummy design such that all patients, including those randomised to oral aripiprazole, received an injection. For patients randomised to aripiprazole once-monthly $400 \mathrm{mg}$ or $50 \mathrm{mg}$, a one-time option to decrease to $300 \mathrm{mg}$ or $25 \mathrm{mg}$, respectively, was permitted, as was a one-time return to the original assigned dose. Patients treated with aripiprazole once-monthly $400 \mathrm{mg}$ or $50 \mathrm{mg}$ received concomitant oral aripiprazole (10-20 mg) for 2 weeks from the date of randomisation, and then placebo tablets thereafter. This dosing strategy was based on previous pharmacokinetic studies that demonstrated that 400 and $300 \mathrm{mg}$ aripiprazole oncemonthly exhibited pharmacokinetic and safety profiles similar to those of multiple, consecutive, daily oral doses of $10-30 \mathrm{mg}$ aripiprazole monotherapy. ${ }^{9}$ For patients randomised to oral aripiprazole, a one-time change in dose (increase or decrease) and a one-time reversal of the change (decrease in dose if previously increased or increase in dose if previously decreased) was permitted as long as the dose remained within the range of $10-30 \mathrm{mg}$ daily.

The study was conducted at 105 centres in Austria, Belgium, Bulgaria, Chile, Croatia, Estonia, France, Hungary, Italy, South Korea, Poland, South Africa, Thailand and the USA between 26 September 2008 and 31 August 2012. In accordance with the Declaration of Helsinki, the ethics committee at each site approved the protocol. After complete description of the study to patients, written informed consent was obtained.

\section{Patients}

Eligible patients were aged 18-60 years and had a diagnosis of schizophrenia according to DSM-IV-TR ${ }^{10}$ criteria for $\geqslant 3$ years and a history of symptom exacerbation when not receiving antipsychotic treatment. Patients needed to have been responsive to antipsychotic treatment (other than clozapine) in the past year. Key exclusion criteria included a DSM-IV-TR diagnosis other than schizophrenia; uncontrolled thyroid function abnormalities; a history of seizures, neuroleptic malignant syndrome, clinically relevant tardive dyskinesia, or other medical condition that would expose the patient to undue risk or interfere with study assessments. Patients who had been admitted to hospital, including for psychosocial reasons, for $>30$ days total of the 90 days preceding entry into phase 1 or 2 of the study after screening were excluded. Individuals were also excluded if they met DSM-IV-TR criteria for substance dependence, including alcohol and benzodiazepines but excluding nicotine and caffeine. Additional exclusion criteria are noted in online supplement DS1.

\section{Assessments}

\section{Primary outcome}

The primary outcome was the Kaplan-Meier estimated impending relapse rate from the date of randomisation to the end of week 26. Patients were assessed for impending relapse, defined as meeting any one or more of the following specified individual criteria at any time during phase 3 :

(a) CGI - Improvement (CGI-I) of $\geqslant 5$ (minimally worse) and either an increase on any of four individual PANSS items (conceptual disorganisation, hallucinatory behaviour, suspiciousness or unusual thought content) to a score $>4$ with an absolute increase of $\geqslant 2$ on that specific item since randomisation, or an increase to $>4$ on one of those PANSS items and an absolute increase of $\geqslant 4$ on the combined score of those items;

(b) admission to hospital as a result of worsening of psychotic symptoms;

(c) CGI-SS score of 4 (severely suicidal) or 5 (attempted suicide) on Part 1 and/or of 6 (much worse) or 7 (very much worse) on Part 2; and

(d) violent behaviour resulting in clinically relevant self-injury, injury to another person or property damage.

\section{Secondary efficacy outcomes}

Time to observed impending relapse and observed rate of impending relapse at week 38 . Secondary efficacy assessments included time to observed impending relapse (time to earliest date that the patient met $\geqslant 1$ of the impending relapse criteria (criteria defined above in the section on Primary outcome)) from randomisation to study end-point (week 38). Observed impending relapse rate at study end-point (week 38) was also compared. Assessments included only those patients who met impending relapse criteria and were calculated as the earliest date the patient met $\geqslant 1$ of the impending relapse criteria minus the randomised date plus 1 . Hazard ratios were used to evaluate the risk of observed impending relapse (see Statistical analyses section).

Responders and remitters. Other secondary efficacy assessments included the percentage of responders (i.e. meeting stability criteria (see Study design)) at the last study visit and the percentage of patients achieving remission according to predefined criteria ${ }^{11}$ (i.e. a score of $\leqslant 3$ on each of eight specific PANSS items, maintained for a period of 6 months: delusions (P1); unusual thought content (G9); hallucinatory behaviour (P3); conceptual disorganisation (P2); mannerisms/posturing (G5); blunted affect (N1); social withdrawal (N4); and lack of spontaneity (N6)).

\section{Other efficacy outcomes}

Additional efficacy outcomes included time to all-cause discontinuation following randomisation; mean change from baseline (defined as the last visit with available data prior to 
randomisation) in PANSS total scores ${ }^{6}$ and CGI-S; and mean CGI-I score at end-point. ${ }^{7}$

\section{Safety outcomes}

Adverse events were examined by frequency, severity, seriousness and according to whether they resulted in discontinuation from the trial. The incidence of treatment-emergent adverse events related to extrapyramidal symptoms (EPS) were summarised by the following event categories: akathisia, dyskinetic, dystonic, Parkinsonism and residual. The following scales were also used to assess EPS: Abnormal Involuntary Movement Scale (AIMS), ${ }^{7}$ Simpson-Angus Scale (SAS), ${ }^{12}$ and Barnes Akathisia Rating Scale (BARS). ${ }^{13}$ The CGI-SS scale and the Columbia Suicide Severity Rating Scale (C-SSRS) were used to assess the risk of suicide events during the study. ${ }^{14}$ Intensity of injection pain was assessed by patients using a visual analogue scale (VAS; $0 \mathrm{~mm}$, no pain to $100 \mathrm{~mm}$, unbearably painful ${ }^{15}$ ) and assessed by investigators in domains of pain, swelling, redness and induration. ${ }^{16}$ The incidence of clinically relevant changes was calculated for vital signs and routine laboratory tests. Mean change from baseline and incidence of clinically relevant changes were calculated for electrocardiogram (ECG) parameters, prolactin concentration and body weight.

\section{Statistical analyses}

The intent-to-treat (ITT) sample included all patients randomised to the double-blind treatment. The efficacy sample included all patients who received at least one dose of treatment and had at least one efficacy outcome assessment in the double-blind, active-controlled phase. The safety sample included all patients who were randomised to double-blind treatment and received at least one dose of treatment in the double-blind, active-controlled phase.

\section{Primary outcome (ITT sample)}

The primary efficacy analysis evaluated the non-inferiority of aripiprazole once-monthly $400 \mathrm{mg}$ to oral aripiprazole (10-30 mg/ day) using the $95 \%$ bilateral confidence interval of the difference in estimated impending relapse rate at week 26 (from KaplanMeier curve estimates using the ITT population). In order to compute this confidence interval, the proportion of patients with impending relapse for each treatment group was computed using the Kaplan-Meier estimate at day 182, and its standard error was computed using the Greenwood formula. The Kaplan-Meier estimated impending relapse rates at week 26 were calculated as 1 minus the proportions of patients free of impending relapse events. Standard errors were calculated using Greenwood's formula. The 95\% confidence interval of difference in the estimated impending relapse rate between aripiprazole once-monthly $400 \mathrm{mg}$ and oral aripiprazole were provided using the pooled standard error with assumption of normality of the estimated difference. A similar methodology was used in computation of the $z$-statistic for comparison of aripiprazole once-monthly $400 \mathrm{mg}$ with aripiprazole once-monthly $50 \mathrm{mg}$ in the estimated impending relapse rate at week 26.

\section{Secondary efficacy outcomes}

Time to observed impending relapse and observed rate of impending relapse at week 38 (ITT sample). Time to observed impending relapse (based on all available relapse data through week 38) for aripiprazole once-monthly $400 \mathrm{mg}$, oral aripiprazole and aripiprazole once-monthly $50 \mathrm{mg}$ was compared using the log-rank test. The observed impending relapse rates were compared between groups using the chi-squared test. Hazard ratios (and two-sided 95\% confidence interval for aripiprazole once-monthly $400 \mathrm{mg} \quad v$. oral aripiprazole and aripiprazole once-monthly $50 \mathrm{mg}$, and for oral aripiprazole $v$. aripiprazole once-monthly $50 \mathrm{mg}$ ) for risk of observed impending relapse were analysed using a Cox proportional hazard model with treatment as the factor.

Responders (ITT sample) and remitters. The proportion of responders at last visit in phase 3 and the proportion of patients achieving remission were analysed using the chi-squared test. Only patients who remained in the trial for at least 6 months were included in the calculation of remission rates.

\section{Other efficacy outcomes}

Time to all-cause discontinuation (ITT sample). Kaplan-Meier curves for the time to discontinuation as a result of all causes were plotted and analysed using the log-rank test.

PANSS, CGI-S, and CGI-I (efficacy sample, last observation carried forward and observed cases). Mean changes from baseline in PANSS total score and CGI-S score were analysed by visit using ANCOVA controlling for treatment and baseline value using last observation carried forward (LOCF). Mean CGI-I scores at week 38 were analysed using the Cochran-Mantel-Haenszel method based on raw mean score statistics using LOCF. Observed cases data are shown in online Table DS1.

\section{Safety outcomes (safety sample, observed cases and LOCF)}

Safety outcomes, including changes from baseline in weight, metabolic parameters and EPS scale scores (BARS, AIMS, and SAS) during phase 3 were analysed using descriptive statistics (observed cases) and/or ANCOVA with treatment as a factor and baseline (score at the end of phase 2) as a covariate (LOCF). In this main report, safety outcomes are reported as observed cases; the online Table DS2 contains observed cases results for metabolic parameters; LOCF findings for safety data are reported in online Table DS3, where available.

\section{Sample size}

Sample sizes were estimated to achieve approximately $93 \%$ power for the primary non-inferiority comparison at $P=0.05$ (two-sided) using large sample normal approximations for the distribution of the difference in binomial proportions. It was assumed that $18 \%$ of patients would meet the criteria for an impending relapse at or before week 26 in the oral aripiprazole treatment arm. The resulting sample size was projected to be 260 patients per arm for aripiprazole once-monthly and oral aripiprazole therapies. The predefined non-inferiority margin was $11.5 \%$. This margin was based on data from a previous trial ${ }^{17}$ that compared relapse rates for oral aripiprazole and placebo showing estimated relapse rates of $37.4 \%$ for oral aripiprazole and $60.6 \%$ for placebo at week 26 , leading to a one-sided $97.5 \%$ lower confidence interval of $15 \%$. Given the potential adherence advantage of an LAI formulation, a conservative margin of $11.5 \%$ was selected for the current trial. Non-inferiority was demonstrated if the upper bound of the 95\% confidence interval was below the predefined margin. If non-inferiority was established, comparison of aripiprazole once-monthly $400 \mathrm{mg}$ with aripiprazole once-monthly $50 \mathrm{mg}$ was performed by examining the difference between the estimated impending relapse 
rates using $z$-statistics for statistical significance at the 0.05 significance level (two-sided).

\section{Results}

\section{Patient disposition and characteristics}

Of 1118 patients screened, 709 patients entered the oral conversion phase (phase 1) and 842 entered the oral stabilisation phase (phase 2), including 228 patients who were already receiving oral aripiprazole and entered phase 2 directly (Fig. 1). A total of 662 patients were randomised to double-blind treatment in phase 3 (Fig. 1). The number of individuals who dropped out because of adverse events was low in the aripiprazole once-monthly $400 \mathrm{mg}$ group and oral aripiprazole group; the main reason for discontinuation during phase 3 was patient withdrawal of consent (Fig. 1). For patients receiving aripiprazole once-monthly $50 \mathrm{mg}$, the main reason for discontinuation was impending relapse with an adverse event.

The ITT sample, efficacy sample, and safety sample each comprised a total of 662 patients, including 265 in the aripiprazole once-monthly $400 \mathrm{mg}$ group, 266 in the oral aripiprazole group, and 131 in aripiprazole once-monthly $50 \mathrm{mg}$ group. Baseline demographic and psychiatric characteristics were similar between treatment groups in the randomised population (Table 1). Treatment exposure data are presented in online supplement DS1.

\section{Efficacy}

Primary outcome (ITT sample)

Kaplan-Meier estimated impending relapse rates at week 26 were $7.12 \%$ for aripiprazole once-monthly $400 \mathrm{mg}, 7.76 \%$ for oral aripiprazole and $21.80 \%$ for aripiprazole once-monthly $50 \mathrm{mg}$
(Fig. 2a). The difference of Kaplan-Meier estimated impending relapse rate by week 26 between aripiprazole once-monthly $400 \mathrm{mg}$ and oral aripiprazole was $-0.64 \%$ (95\% CI -5.26 to 3.99 ), which confirmed non-inferiority by excluding the predefined non-inferiority margin of $11.5 \%$. Superiority of aripiprazole once-monthly $400 \mathrm{mg}$ was shown $v$. aripiprazole once-monthly $50 \mathrm{mg}$ ( $P \leqslant 0.001$ from $z$-statistics), confirming assay sensitivity. Observed impending relapse rates at week 26 were similar to the Kaplan-Meier estimate impending relapse rates: aripiprazole once-monthly $400 \mathrm{mg}$, 6.79\% (18/265); oral aripiprazole $(10-30 \mathrm{mg}), 7.14 \% \quad(19 / 266)$; aripiprazole oncemonthly $50 \mathrm{mg}, 18.32 \%$ (24/131); confirming non-inferiority for aripiprazole once-monthly $400 \mathrm{mg} v$. oral aripiprazole $(95 \% \mathrm{CI}$ -5.06 to $4.36, P=0.8740$ ), and superiority $v$. aripiprazole oncemonthly $50 \mathrm{mg}(95 \% \mathrm{CI}-19.38$ to $-3.67, P=0.0005)$.

\section{secondary efficacy outcomes}

Time to observed impending relapse and observed rate of impending relapse at week 38 (ITT sample). Time to observed impending relapse for aripiprazole once-monthly $400 \mathrm{mg}$ was similar to that for oral aripiprazole (log-rank test, $P=0.992$ ), with both treatments demonstrating statistically significant delays in impending relapse $v$. aripiprazole once-monthly $50 \mathrm{mg}$ $(P<0.0001)$ up to week 38 (Fig. 2b). The proportion of observed impending relapsers and the risk of observed impending relapse at week 38 showed comparable and statistically significant benefits with aripiprazole once-monthly $400 \mathrm{mg} v$. aripiprazole oncemonthly $50 \mathrm{mg}(P<0.0001$; Table 2$)$.

Responders (ITT sample) and remitters. There was a statistically significant greater proportion of responders with aripiprazole once-monthly $400 \mathrm{mg} \quad v$. aripiprazole once-monthly $50 \mathrm{mg}$

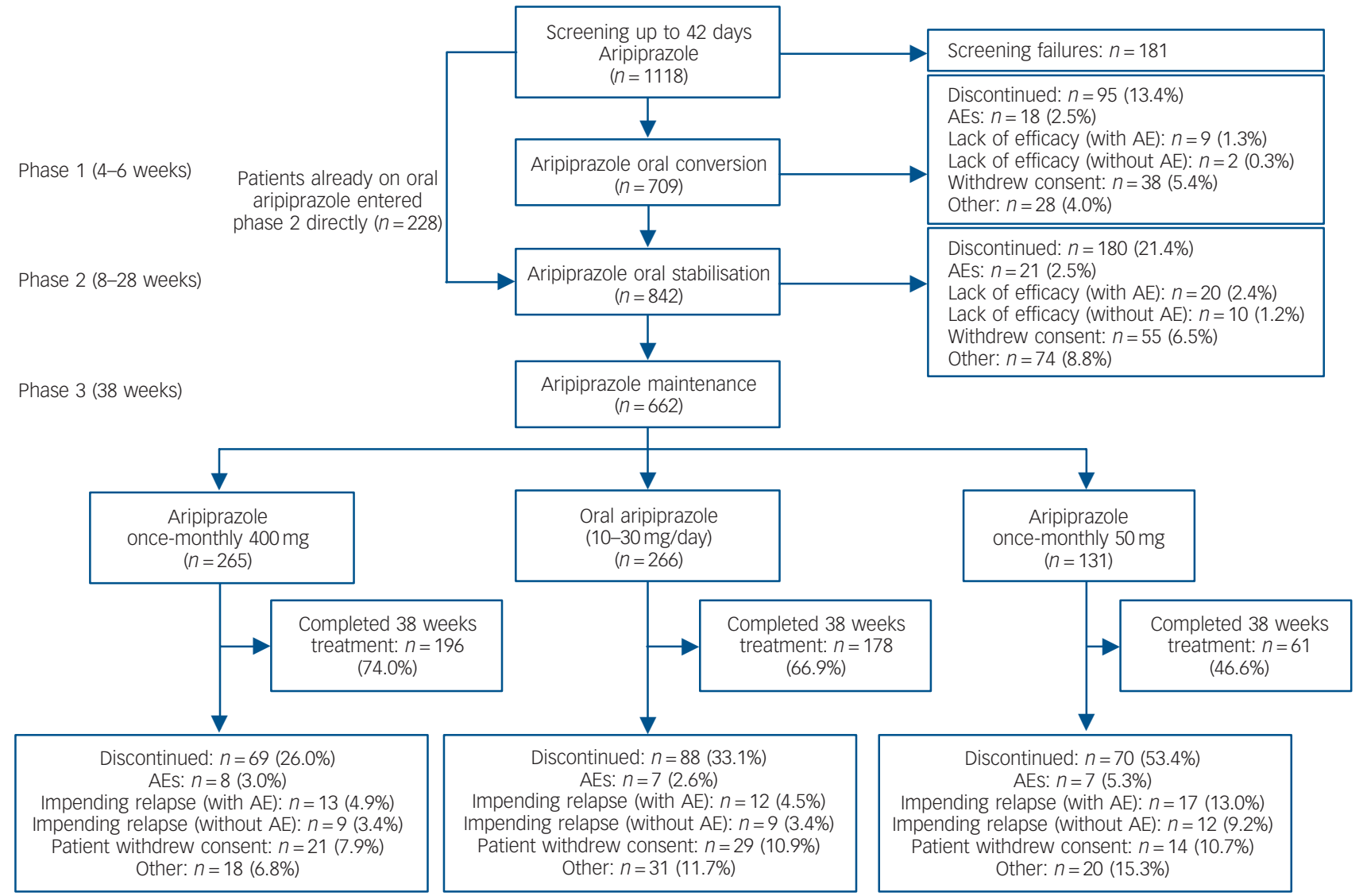

Fig. 1 Patient flow throughout the study. AE, adverse event. 


\begin{tabular}{|c|c|c|c|}
\hline & $\begin{array}{l}\text { Aripiprazole once-monthly } 400 \mathrm{mg} \\
\qquad(n=265)\end{array}$ & $\begin{array}{l}\text { Oral aripiprazole } 10-30 \mathrm{mg} \\
\qquad(n=266)\end{array}$ & $\begin{array}{l}\text { Aripiprazole once-monthly } 50 \mathrm{mg} \\
\qquad(n=131)\end{array}$ \\
\hline Age, years: mean (s.d.) & $41.7(10.4)$ & $41.2(10.8)$ & $40.2(9.6)$ \\
\hline Gender, male: $n(\%)$ & $160(60.4)$ & $168(63.2)$ & $78(59.5)$ \\
\hline \multicolumn{4}{|l|}{ Ethnicity, $n(\%)$} \\
\hline White & $160(60.4)$ & $153(57.5)$ & $74(56.5)$ \\
\hline Black or African American & $56(21.1)$ & $64(24.1)$ & $33(25.2)$ \\
\hline Asian & $29(10.9)$ & $26(9.8)$ & $14(10.7)$ \\
\hline Other & $20(7.5)$ & $23(8.6)$ & $10(7.6)$ \\
\hline Weight, kg: mean (s.d.) & $83.4(20.9)$ & $83.7(19.2)$ & $82.9(24.4)$ \\
\hline Body mass index, $\mathrm{kg} / \mathrm{m}^{2}$ : mean (s.d.) & $28.9(6.7)$ & $28.7(5.9)$ & $28.7(7.9)$ \\
\hline Age at first diagnosis, years: mean (s.d.) & $28.2(9.3)$ & $26.9(9.1)$ & $26.3(7.9)$ \\
\hline PANSS total score, mean (s.d.) & $58.0(12.9)$ & $56.6(12.7)$ & $56.1(12.6)$ \\
\hline CGI-Severity score, mean (s.d.) & $3.1(0.7)$ & $3.1(0.8)$ & $3.0(0.8)$ \\
\hline CGI-Improvement score, mean (s.d.) & $3.2(0.9)$ & $3.3(0.9)$ & $3.1(1.0)$ \\
\hline
\end{tabular}

(a)

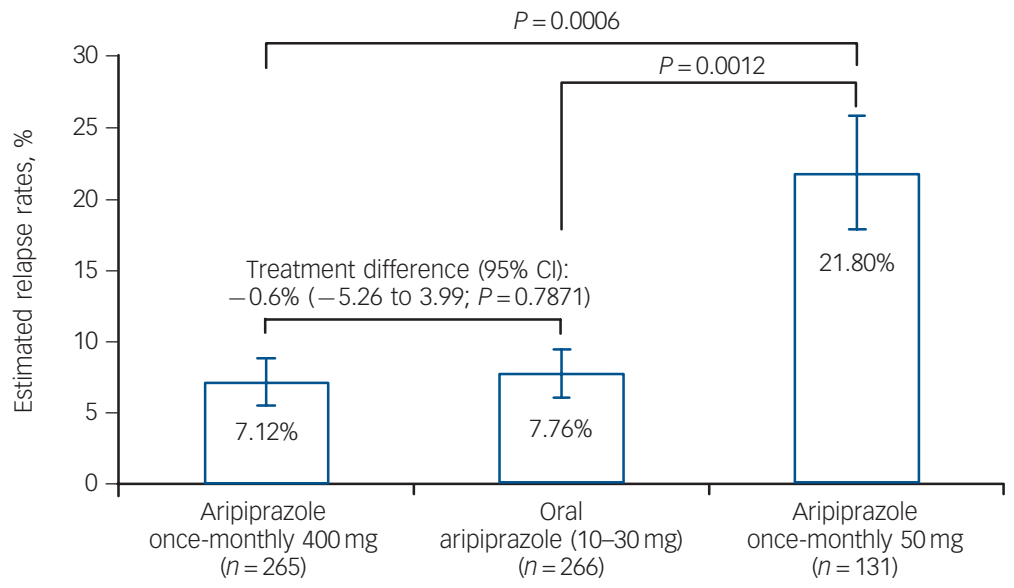

(b)

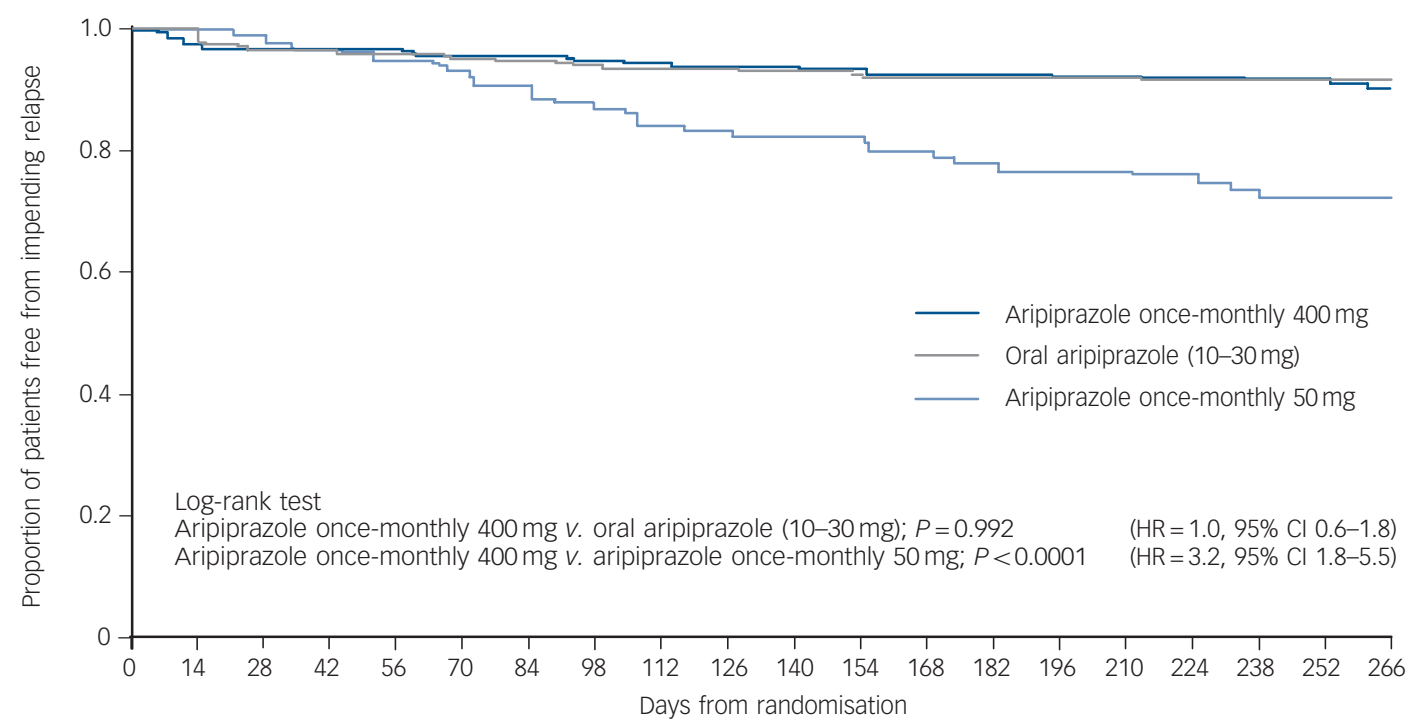

Number of patients at risk

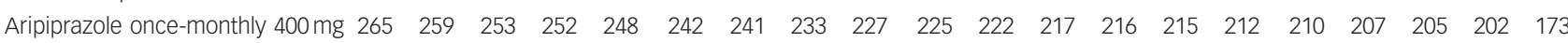

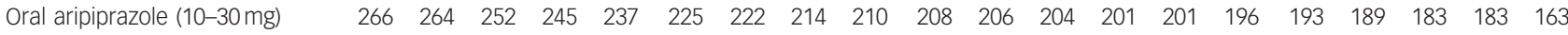

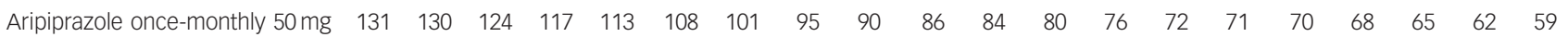

Fig. 2 (a) Kaplan-Meier estimated impending relapse rates at week 26 (intention-to-treat (ITT) sample) and (b) time to observed impending relapse at week 38 (ITT sample).

In (a) whiskers indicate standard error. HR, hazard ratio. 
$(P=0.0001$, Table 2$)$. The proportion of remitters did not show any statistically significant differences between treatment groups, although the proportion of patients remaining in the study for 6 months in the aripiprazole once-monthly $50 \mathrm{mg}$ group was lower $(n=72 / 131,55.0 \%)$ than in the aripiprazole once-monthly $400 \mathrm{mg}$ group $(n=215 / 265,81.1 \%)$ or the oral aripiprazole group $(n=201 / 266,75.6 \%)$ (Table 2).

\section{Other efficacy outcome measures}

Time to all-cause discontinuation (ITT sample). A statistically significant advantage on the Kaplan-Meier time to discontinuation favouring aripiprazole once-monthly $400 \mathrm{mg}$ was observed $v$. oral aripiprazole $(P<0.05)$ and $v$. aripiprazole once-monthly $50 \mathrm{mg}$ $(P<0.0001$, Fig. 3a). The all-cause discontinuation rate (a measure of effectiveness) was $25.3 \%(n=67 / 265)$ for aripiprazole oncemonthly $400 \mathrm{mg}, 32.7 \%(n=87 / 266)$ for oral aripiprazole and $53.4 \%(n=70 / 131)$ for aripiprazole once-monthly $50 \mathrm{mg}$.

PANSS, CGI-S, and CGI-I (efficacy sample, LOCF). Symptom measures using PANSS, CGI-S and CGI-I showed statistically significant differences for aripiprazole once-monthly $400 \mathrm{mg} v$. both oral aripiprazole and aripiprazole once-monthly $50 \mathrm{mg}$ (Table 2). Mean changes from baseline to end-point in adjusted mean PANSS total score (efficacy sample, LOCF) are shown in Fig. 3b. Statistically significant differences in mean change in PANSS total score between aripiprazole once-monthly $400 \mathrm{mg}$ and oral aripiprazole were observed at weeks 10-14, 18, 26 and study end-point $(P<0.05)$. Statistically significant differences in the aripiprazole once-monthly $400 \mathrm{mg}$ group $v$. the aripiprazole once-monthly $50 \mathrm{mg}$ group were observed at week 4 and from week 8 onwards $(P<0.05)$. Data for other efficacy end-points in the efficacy sample for observed cases can be found in online Table DS1.

\section{Safety and tolerability (safety sample, observed cases)}

The most common treatment-emergent adverse events $(\geqslant 5 \%$ in any group) are presented in Table 3. For aripiprazole once-monthly $400 \mathrm{mg}$, insomnia, akathisia, headache and weight decrease/increase were reported by $9-12 \%$ of patients (Table 3 ). The majority of treatment-emergent adverse events reported in the randomised phase were mild or moderate in severity.

During the randomised phase, serious treatment-emergent adverse events were reported in a total of 41/662 (6.2\%) patients: $15 / 265(5.7 \%)$ treated with aripiprazole once-monthly $400 \mathrm{mg}$; $15 / 266$ (5.6\%) treated with oral aripiprazole; and 11/131 (8.4\%) treated with aripiprazole once-monthly $50 \mathrm{mg}$. Serious treatmentemergent adverse events reported in $\geqslant 2 \%$ of patients were only observed for patients treated with aripiprazole once-monthly $50 \mathrm{mg}$, and were psychiatric disorder $(n=4,3.1 \%)$ and schizophrenia $(n=3,2.3 \%)$. Two deaths were reported, one as a result of cardiac arrest in the oral aripiprazole group (15 mg dose, 51-year-old male) and one as a result of suicide in the aripiprazole once-monthly $50 \mathrm{mg}$ group (44-year-old male). Neither death was considered by the investigator to be related to the trial medication.

During the randomised phase, discontinuation of doubleblind medication due to treatment-emergent adverse events (including impending relapse with adverse events) was reported in $21 / 265(7.9 \%)$ patients in the aripiprazole once-monthly $400 \mathrm{mg}$ group, $19 / 266(7.1 \%)$ patients in the oral aripiprazole

\section{Table 2 Secondary and other efficacy outcomes (week 38)}

\begin{tabular}{|c|c|c|c|c|c|}
\hline \multirow[b]{2}{*}{ Efficacy outcome } & \multirow[b]{2}{*}{$\begin{array}{l}\text { Aripiprazole once- } \\
\text { monthly } 400 \mathrm{mg} \\
\quad(n=265)\end{array}$} & \multirow[b]{2}{*}{$\begin{array}{l}\text { Oral aripiprazole } \\
\begin{array}{l}10-30 \mathrm{mg} \\
(n=266)\end{array}\end{array}$} & \multirow[b]{2}{*}{$\begin{array}{l}\text { Aripiprazole once- } \\
\text { monthly } 50 \mathrm{mg} \\
\qquad(n=131)\end{array}$} & \multicolumn{2}{|c|}{$P$} \\
\hline & & & & $\begin{array}{l}\text { Aripiprazole once- } \\
\text { monthly } 400 \mathrm{mg} v \text {. } \\
\text { oral aripiprazole } \\
10-30 \mathrm{mg}\end{array}$ & $\begin{array}{l}\text { Aripiprazole once- } \\
\text { monthly } 400 \mathrm{mg} v \text {. } \\
\text { aripiprazole once- } \\
\text { monthly } 50 \mathrm{mg}\end{array}$ \\
\hline $\begin{array}{l}\text { Observed impending relapse }{ }^{\text {(ITT samp }} \\
\text { Proportion of observed impending } \\
\text { relapsers, \% ( }(n / N) \\
\text { Risk of observed impending relapse } \\
\text { V. aripiprazole once-monthly } 50 \mathrm{mg} \text {, } \\
\text { HR }(95 \% \mathrm{Cl}) P\end{array}$ & $\begin{array}{l}8.30(22 / 265) \\
\\
3.158(1.81-5.50) \\
\quad<0.0001\end{array}$ & $\begin{array}{c}7.89(21 / 266) \\
3.131(1.78-5.49) \\
<0.0001\end{array}$ & $22.14(29 / 131)$ & 0.8635 & $<0.0001$ \\
\hline \multicolumn{6}{|l|}{$\begin{array}{l}\text { Responders (ITT sample) and remitters, } \\
\%(n / N)\end{array}$} \\
\hline $\begin{array}{l}\text { PANSS Total score (efficacy sample, LO } \\
n \\
\text { Baseline, least square mean (s.e.) } \\
\text { Change from baseline at week 38, } \\
\text { least square mean (s.e.) }\end{array}$ & $\begin{array}{c}263 \\
57.94(0.79) \\
-1.66(0.72)\end{array}$ & $\begin{array}{c}266 \\
56.57(0.78) \\
0.58(0.71)\end{array}$ & $\begin{array}{c}131 \\
56.08(1.11) \\
3.08(1.01)\end{array}$ & $\begin{array}{l}0.2179 \\
0.0272\end{array}$ & $\begin{array}{l}0.1751 \\
0.0002\end{array}$ \\
\hline $\begin{array}{l}\text { CGI - Severity (efficacy sample, LOCF) } \\
n \\
\text { Baseline, least square mean (s.e.) } \\
\text { Change from baseline at week 38, } \\
\text { least square mean (s.e.) }\end{array}$ & $\begin{array}{c}259 \\
3.12(0.05) \\
-0.13(0.05)\end{array}$ & $\begin{array}{c}263 \\
3.09(0.05) \\
0.05(0.05)\end{array}$ & $\begin{array}{c}129 \\
2.95(0.07) \\
0.23(0.07)\end{array}$ & $\begin{array}{l}0.7262 \\
0.0123\end{array}$ & $\begin{array}{r}0.0605 \\
<0.0001\end{array}$ \\
\hline $\begin{array}{l}\text { CGI - Improvement (efficacy sample, LO } \\
\text { n } \\
\text { Baseline, mean (s.d.) } \\
\text { At week 38, mean (s.d.) }\end{array}$ & $\begin{array}{c}265 \\
3.24(0.91) \\
3.27(1.16)^{c}\end{array}$ & $\begin{array}{c}266 \\
3.26(0.90) \\
3.66(1.16)\end{array}$ & $\begin{array}{c}131 \\
3.08(1.02) \\
4.02(1.32)\end{array}$ & $\begin{array}{l}0.7830 \\
0.0002\end{array}$ & $\begin{array}{r}0.1306 \\
<0.0001\end{array}$ \\
\hline $\begin{array}{l}\text { ITT, intent to treat; HR, hazard ratio; PANSS, } P \\
\text { a. Impending relapse was defined as in Metho } \\
\text { b. Only patients who remained in the trial for } \\
\text { calculation of remission rates. Remission was } \\
\text { c. } n=263 \text {. }\end{array}$ & $\begin{array}{l}\text { nd Negative Syndrom } \\
6 \text { months (i.e. the pro } \\
\text { as in Method. }\end{array}$ & $\begin{array}{l}\text { ale; LOCF, last obse } \\
\text { on of patients with }\end{array}$ & $\begin{array}{l}\text { carried forward; CG } \\
\text { ending relapse at } 6\end{array}$ & $\begin{array}{l}\text { ical Global Impression. } \\
\text { hs) were included as th }\end{array}$ & enominator in the \\
\hline
\end{tabular}


(a)

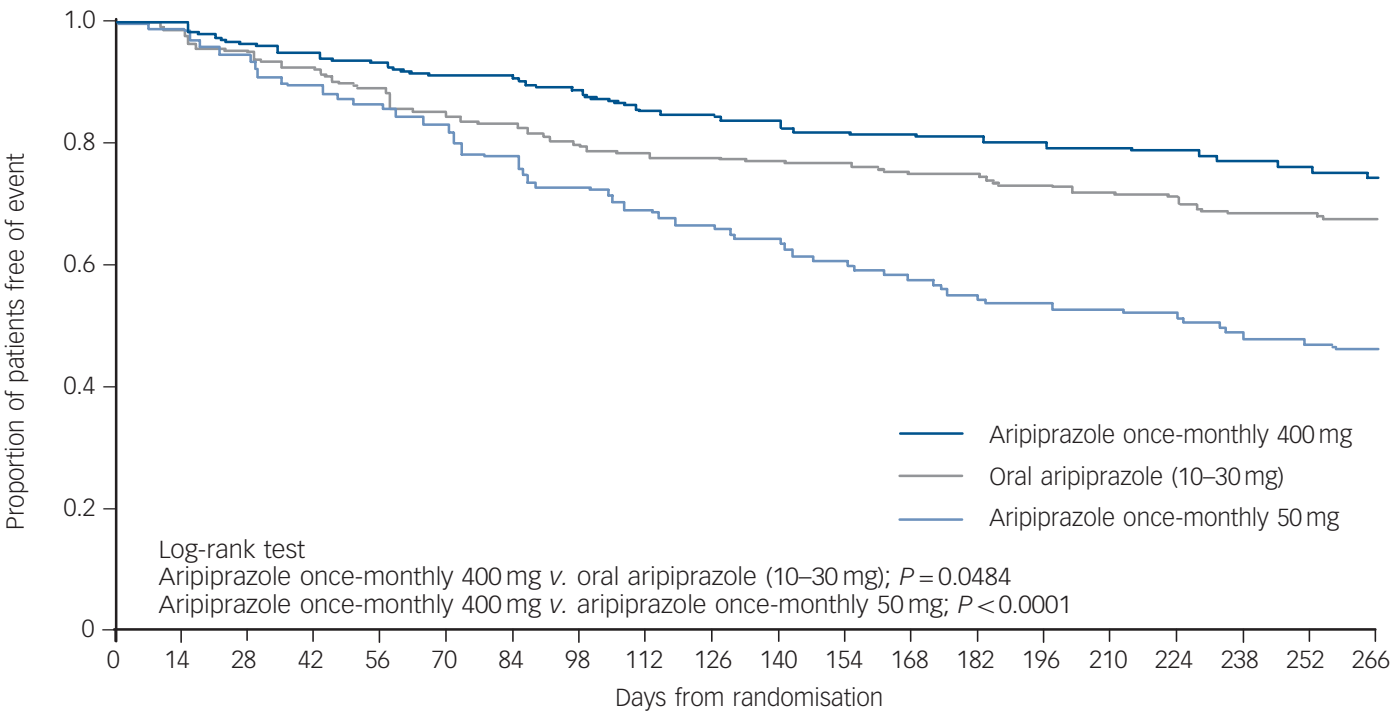

Number of patients at risk on aripiprazole:

$\begin{array}{lrrrrrrrrrrrrrrrrrrrr}\text { once-monthly 400 mg } & 265 & 259 & 253 & 252 & 248 & 242 & 241 & 233 & 227 & 225 & 222 & 217 & 216 & 215 & 212 & 210 & 207 & 205 & 202 & 173 \\ \text { oral (10-30 mg) } & 266 & 264 & 252 & 245 & 237 & 225 & 222 & 214 & 210 & 208 & 206 & 204 & 201 & 201 & 196 & 193 & 189 & 183 & 183 & 163 \\ \text { once-monthly 50 mg } & 131 & 130 & 124 & 117 & 113 & 108 & 101 & 95 & 90 & 86 & 84 & 80 & 76 & 72 & 71 & 70 & 68 & 65 & 62 & 59\end{array}$

(b)

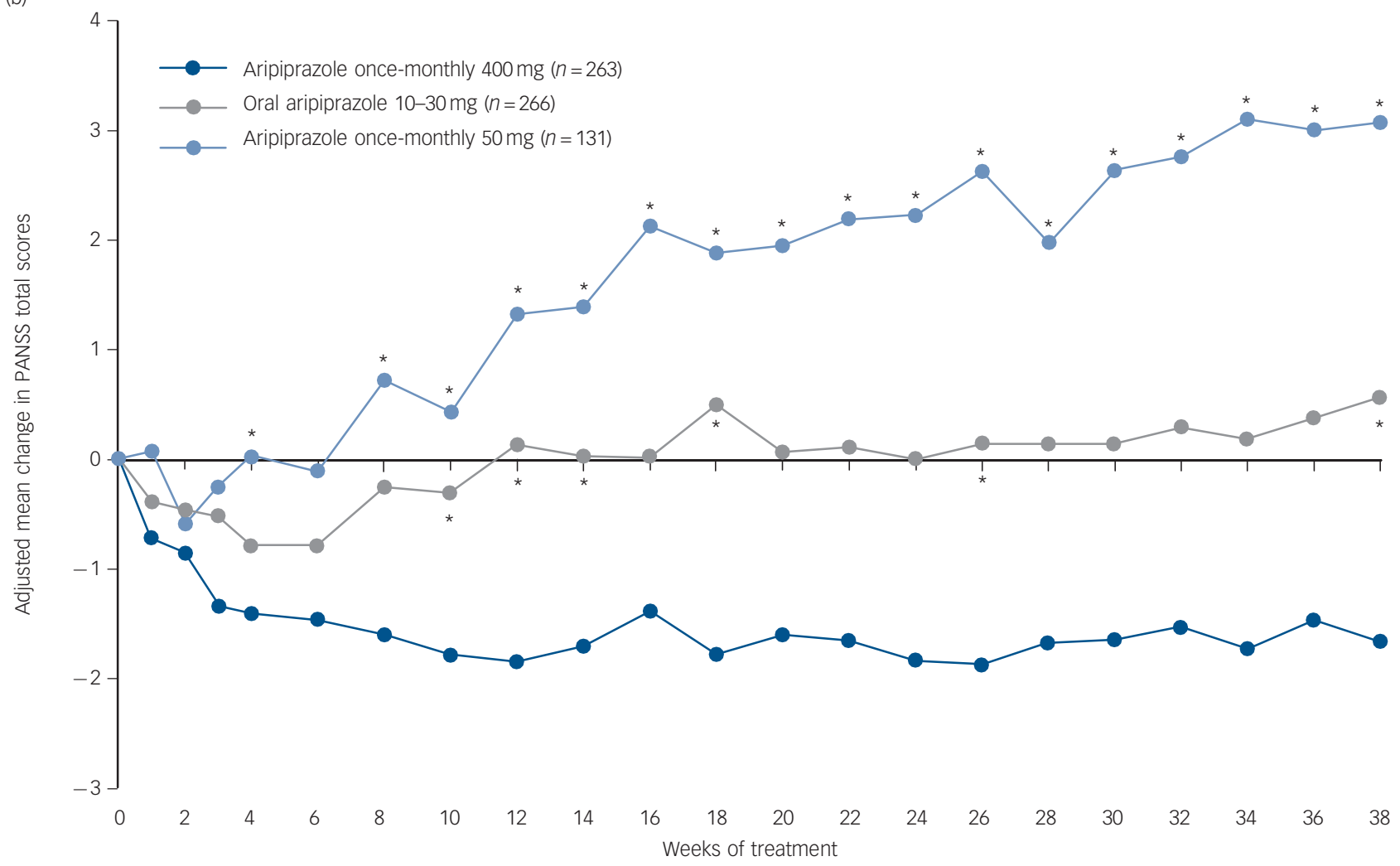

Fig. 3 (a) Time to all-cause discontinuation during phase 3 (intention-to-treat sample); (b) adjusted mean change of PANSS total score in phase 3 (efficacy sample, last-observation-carried-forward).

(a) Refers to patients that discontinued prior to or on day 280 in phase 3 . (b) $* P<0.05$ v. aripiprazole once-monthly $400 \mathrm{mg}$. PANSS, Positive and Negative Syndrome Scale.

group and $24 / 131(18.3 \%)$ of patients in the aripiprazole oncemonthly $50 \mathrm{mg}$ group. Treatment-emergent adverse events resulting in discontinuation that occurred in $\geqslant 2 \%$ of patients in any treatment group were psychotic disorder $(4 / 265(1.5 \%)$ aripiprazole once-monthly $400 \mathrm{mg}$; 5/266 (1.9\%) oral aripiprazole; $8 / 131(6.1 \%)$ aripiprazole once-monthly $50 \mathrm{mg})$ and schizophrenia (8/265 (3.0\%) aripiprazole once-monthly $400 \mathrm{mg} ; 5 / 266(1.9 \%)$ oral aripiprazole; $9 / 131(6.9 \%)$ aripiprazole once-monthly
$50 \mathrm{mg}$ ). No patients discontinued study treatment because of akathisia.

During the randomised phase, 58/265 (21.9\%) patients in the aripiprazole once-monthly $400 \mathrm{mg}$ group, $31 / 266(11.7 \%)$ in the oral aripiprazole group and 16/131 (12.2\%) in the aripiprazole once-monthly $50 \mathrm{mg}$ group had treatment-emergent EPS and EPS-related treatment-emergent adverse events. These EPS and EPS-related events reported by $\geqslant 5 \%$ of patients were akathisia 


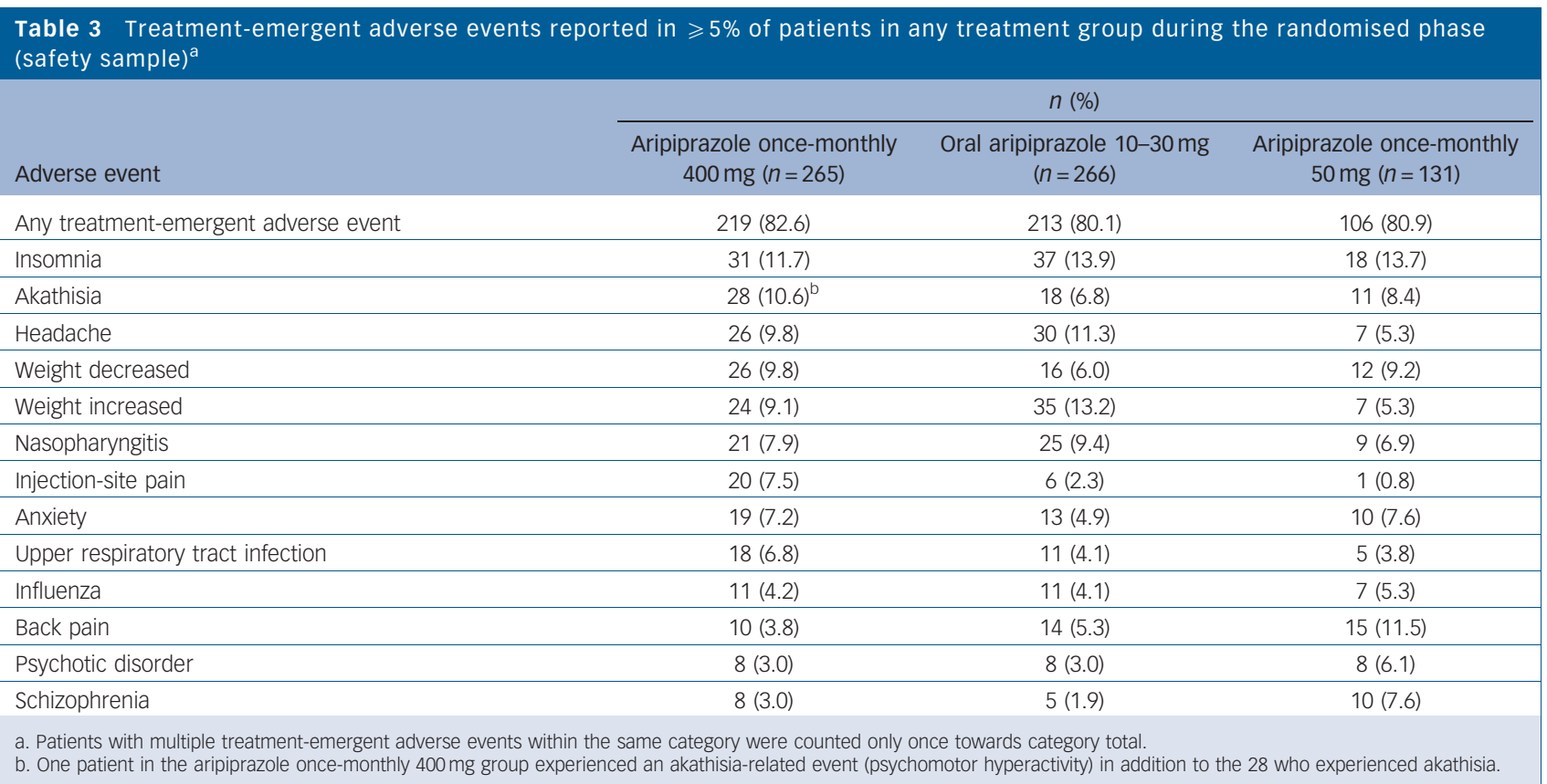

events $(29 / 265,10.9 \%)$ and Parkinsonism events $(15 / 265,5.7 \%)$ in the aripiprazole once-monthly $400 \mathrm{mg}$ group, akathisia $(18 / 266$, $6.8 \%)$ in the oral aripiprazole group and akathisia (11/131, $8.4 \%)$ and Parkinsonism events $(7 / 131,5.3 \%)$ in the aripiprazole once-monthly $50 \mathrm{mg}$ group. Extrapyramidal symptoms were also monitored using physician- and patient-rated scales (Table 4). No statistically significant differences in SAS, AIMS or BARS least squares mean score changes were observed for aripiprazole oncemonthly $400 \mathrm{mg} \quad v$. aripiprazole once-monthly $50 \mathrm{mg}$; the difference in BARS was statistically significant for aripiprazole once-monthly $400 \mathrm{mg}(0.06) \quad v$. oral aripiprazole $(-0.05)$. The score for CGI-SS and the C-SSRS suicidal ideation intensity total score remained stable across treatment groups throughout the double-blind active-controlled phase (Table 4). See online Table DS3 for LOCF data on EPS and suicidality in the safety sample.

Rates of concomitant anticholinergic use during phase 3 were $19.6 \%(n=52 / 265$; mean daily dose, $1.61 \mathrm{mg})$ for aripiprazole once-monthly $400 \mathrm{mg}, 17.3 \% \quad(n=46 / 266$; mean daily dose, $1.50 \mathrm{mg})$ for oral aripiprazole, and $13.7 \%(n=18 / 131$; mean daily dose, $1.66 \mathrm{mg}$ ) for aripiprazole once-monthly $50 \mathrm{mg}$. Concomitant benzodiazepine use data are reported in the online supplement DS1.

Mean changes in body weight at week 38 of $+0.1 \mathrm{~kg}$ (s.d. $=4.8$ ), $+1.0 \mathrm{~kg}$ (s.d. $=4.8$ ), and $-1.6 \mathrm{~kg}$ (s.d. $=7.4)$ for aripiprazole oncemonthly $400 \mathrm{mg}$, oral aripiprazole, and aripiprazole once-monthly $50 \mathrm{mg}$, respectively. The difference was statistically significant at week $38 \quad(P<0.05)$ for aripiprazole once-monthly $400 \mathrm{mg} v$. aripiprazole once-monthly $50 \mathrm{mg}$. The incidence of clinically relevant weight gain ( $\geqslant 7 \%$ increase in weight from baseline) at any time during the randomised phase was $15.9 \%(n=42 / 264)$ for aripiprazole once-monthly $400 \mathrm{mg}, 16.2 \%(n=43 / 266)$ for oral aripiprazole and $6.1 \%(n=8 / 131)$ for aripiprazole once-monthly $50 \mathrm{mg}$. The incidence of clinically relevant weight loss $(\geqslant 7 \%$ decrease in weight from baseline) at any time during the randomised phase was $15.2 \%(n=40 / 264)$ for aripiprazole once-monthly $400 \mathrm{mg}, 10.2 \%(n=27 / 266)$ for oral aripiprazole and $13.7 \%$ $(n=18 / 131)$ for aripiprazole once-monthly $50 \mathrm{mg}$.

There were no differences in mean change in metabolic parameters, and the incidence of potentially clinically relevant new-onset metabolic parameter abnormalities was low and similar among treatment groups (online Table DS2). Similar findings were observed for prolactin (online Table DS2). There were also no clinically relevant changes in ECG parameters and no incidents of new-onset QTcF (QT interval as corrected for heart rate by Fridericia's formula) increases $>500 \mathrm{~ms}$ during double-blind treatment.

Injection-site pain occurred in $7.5 \%(20 / 265)$ of patients in the aripiprazole once-monthly $400 \mathrm{mg}$ group, $2.3 \%$ (6/266) of the oral aripiprazole group and $0.8 \%(1 / 131)$ of the aripiprazole once-monthly $50 \mathrm{mg}$ group. Mean intensity of pain, measured using a patient-reported 100-point VAS scale $(0 \mathrm{~mm}$, no pain; $100 \mathrm{~mm}$, unbearably painful) showed mild pain during the double-blind treatment phase, with reductions being reported from the first to last injection with aripiprazole once-monthly $400 \mathrm{mg} \quad(5.6-3.7 \mathrm{~mm})$, oral aripiprazole $(4.9-3.5 \mathrm{~mm})$ and aripiprazole once-monthly $50 \mathrm{mg}(3.3-2.4 \mathrm{~mm})$. Absence of any pain, redness, swelling and induration by investigators' evaluations was found for the majority of patients following the first and last injections of aripiprazole once-monthly $400 \mathrm{mg}$.

\section{Discussion}

\section{Main findings}

The current study showed that aripiprazole once-monthly at a dose of $400 \mathrm{mg}$ is non-inferior to oral aripiprazole $(10-30 \mathrm{mg})$ and superior to aripiprazole once-monthly $50 \mathrm{mg}$ on the primary outcome of Kaplan-Meier estimated rate of impending relapse at week 26. The secondary outcome, delay in time to observed impending relapse, was statistically significant with aripiprazole once-monthly $400 \mathrm{mg}$ compared with aripiprazole once-monthly $50 \mathrm{mg}$ at week 38. Also, the delay in time to all-cause discontinuation (non-primary/non-secondary outcome) was statistically significant with aripiprazole once-monthly $400 \mathrm{mg}$ compared with both the oral and aripiprazole once-monthly $50 \mathrm{mg}$ groups.

\section{Other findings}

On other (non-primary/non-secondary) efficacy measures (PANSS, CGI-S and CGI-I), there were statistically significant differences for aripiprazole once-monthly $400 \mathrm{mg} \quad v$. both aripiprazole once-monthly $50 \mathrm{mg}$ and oral aripiprazole. Although statistically significant, the clinical relevance of the absolute changes in PANSS total score is difficult to interpret. Prior 


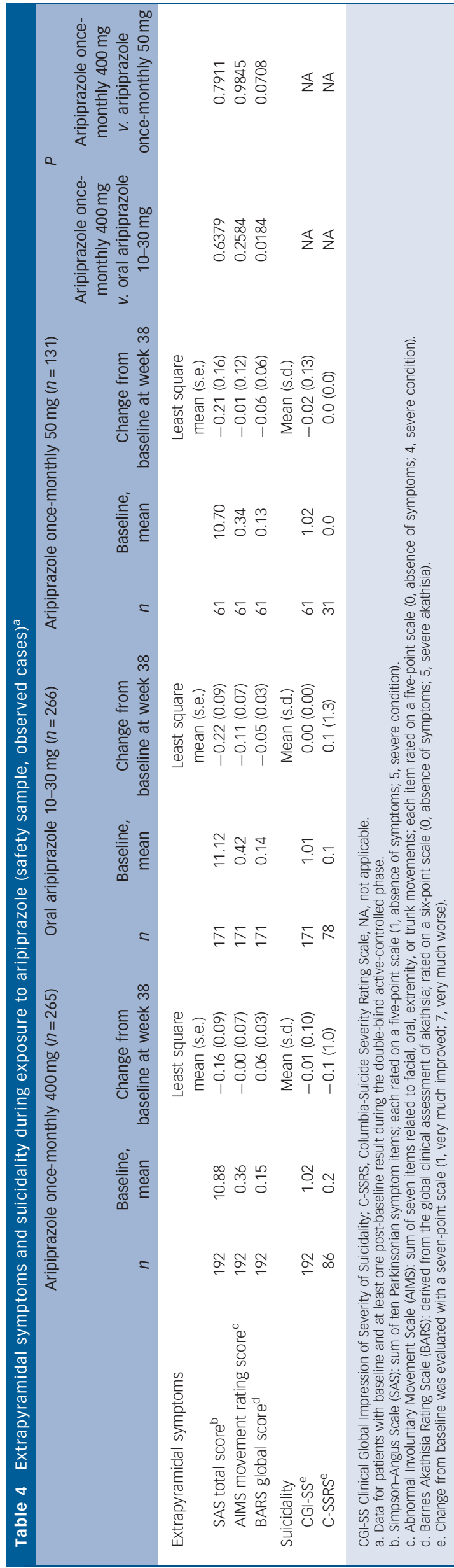

research on the association between CGI-S and PANSS scores suggests that a mild CGI-S score (i.e. 3 ) corresponds with a PANSS total score of $55-62,{ }^{18}$ indicating that at baseline in the doubleblind, active-controlled phase of the current study, patients demonstrated mild symptoms across treatment groups. Prior research also indicates that no change on the CGI-I (i.e. CGI-I score of 4) corresponds with PANSS percentage change score reductions of $2-3 \% .{ }^{18}$ Thus, in the current study, the statistically significant treatment differences favouring aripiprazole oncemonthly $400 \mathrm{mg} v$. oral aripiprazole and aripiprazole once-monthly $50 \mathrm{mg}$ in PANSS total score may be of minimal clinical relevance (treatment differences in least square mean change scores ranged from $\sim 2$ to 5 points) because the overall disease severity of patients in all three groups was relatively unchanged. Modest changes in PANSS may be consistent with clinical expectations for patients who were already stabilised with oral aripiprazole therapy.

The safety profile of aripiprazole once-monthly was comparable with oral aripiprazole and consistent with that reported for oral aripiprazole in previous registrational maintenance studies. ${ }^{3,17,19}$ The safety profile reported here is also consistent with data from another maintenance study of aripiprazole once-monthly $400 \mathrm{mg} v$. placebo. ${ }^{3}$ Metabolic changes, weight changes and EPS-related changes were generally comparable across registrational maintenance studies of both oral and once-monthly formulations. The clinical relevance of the statistically significant change in BARS global score observed at week 38 with aripiprazole once-monthly $400 \mathrm{mg} \quad v$. oral aripiprazole in the current study is unknown. In general, the overall rates of treatment-emergent adverse events, including akathisia, were lower in the maintenance study reported by Kane et $a l,^{3}$ possibly because of the study design, which required patients to be stabilised on aripiprazole once-monthly for 3 months prior to randomisation. There was no requirement for stabilisation on once-monthly aripiprazole prior to randomisation in the current study. As previously observed, ${ }^{3}$ injections were well tolerated; numerically higher rates of injection-site pain treatment-emergent adverse events were observed for aripiprazole once-monthly $400 \mathrm{mg}$ compared with aripiprazole once-monthly $50 \mathrm{mg}$; however, across all treatment groups, patients reported mild injection pain, with reductions in self-reported injection pain scores from the first to last injection.

\section{Advantages and disadvantages of LAls}

Recent guideline updates from the World Federation of Societies of Biological Psychiatry ${ }^{20}$ suggest that the potential advantages of LAI antipsychotics $v$. oral antipsychotics include improved adherence to treatment, avoidance of gastrointestinal absorption problems and circumvention of first-pass hepatic metabolism. Potential disadvantages of LAIs include diminished flexibility of administration, potential for injection-site reactions and delayed attenuation of adverse effects after treatment discontinuation. ${ }^{20}$ The potential benefit of aripiprazole once-monthly $400 \mathrm{mg}$ over the oral and $50 \mathrm{mg}$ dose on time to all-cause discontinuation complements a recent large national cohort study in Finland of 2588 patients admitted to hospital with newly diagnosed schizophrenia, which found that patients treated with LAIs had a lower risk of readmissions to hospital in comparison with those treated with oral formulations of the same antipsychotic medications. ${ }^{21}$ In contrast, a controlled clinical study in the USA reported rates of readmission that were comparable between LAI risperidone and any oral antipsychotic therapy. ${ }^{22}$ Recent meta-analyses suggest that differences between oral and LAI formulations are less likely to be found in controlled clinical trials where adherence is enhanced owing to multiple clinic visits and more likely to be observed in naturalistic studies. ${ }^{23,24}$ 


\section{Limitations}

In the current study, treatment initiation of aripiprazole oncemonthly in the randomised phase was carried out in patients who had been stabilised with oral aripiprazole. However, in clinical practice, patients may be switched directly from their current oral antipsychotic to an LAI antipsychotic. This difference from real-life clinical populations may limit the generalisability of our findings. The study population was also limited to patients with chronic schizophrenia of mild severity, which may have contributed to the low rates of relapse and may also limit the generalisability of our findings. Also, because of the very low initial relapse rates, the primary outcome was adjusted (as approved by the EMA; see online supplement DS1) from time to observed impending relapse at week 38 to Kaplan-Meier estimated relapse rates at week 26 , because time as a variable can have a disproportional impact on time to events when event rates are low. Revising the primary outcome after the trial started may have introduced some bias; however, the total impending relapse events remained low for the duration of the study, the estimated sample size was slightly increased and non-inferiority $v$. oral aripiprazole was clearly demonstrated. In addition, the study did not consider the potential for multiple testing concerns, which may have limited the strength of the prespecified statistical analysis plan for secondary and other efficacy outcomes. Another potential limitation is that our trial may not have been long enough to fully detect potential differences between the oncemonthly and the oral formulations of aripiprazole.

\section{W. Wolfgang Fleischhacker, MD, Department of Psychiatry and Psychotherapy, Medical University Innsbruck, Innsbruck, Austria; Raymond Sanchez, MD, Pamela P. Perry, MS, Otsuka Pharmaceutical Development \& Commercialization, Inc., Princeton, New Jersey, USA; Na Jin, MS, Otsuka Pharmaceutical Development \& Commercialization, Inc., Rockville, Maryland, USA; Timothy Peters-Strickland, MD Brian R. Johnson, MS, Ross A. Baker, PhD, MBA, Otsuka Pharmaceutical Development \& Commercialization, Inc., Princeton, New Jersey, USA; Anna Eramo, MD, Lundbeck LC, Deerfield, Illinois, USA: Robert D. McQuade, PhD, william H. Carson, MD, Otsuka Pharmaceutical Development \& Commercialization, Inc., Princeton, New Jersey, USA; David Walling, PhD, Collaborative Neuroscience Network, Inc., Garden Grove, California, USA; John M. Kane, MD, The Zucker Hillside Hospital, Glen Oaks, and the Hofstra North Shore-LIJ School of Medicine, Hempstead} New York, USA

Correspondence: W. Wolfgang Fleischhacker, MD, Division of Biologica Psychiatry, Department of Psychiatry and Psychotherapy, Medical University Innsbruck, Anichstrasse 35, A-6020 Innsbruck, Austria. Email: wolfgang.fleischhacker@i-med.ac.at

First received 21 Jun 2013, final revision 29 Jan 2014, accepted 27 Feb 2014

\section{Funding}

This study was supported by Otsuka Pharmaceutical Commercialization, Inc. (Tokyo, Japan). Editorial support for the preparation of this manuscript was provided by Suzanne Patel at Ogilvy Healthworld Medical Education and Amy Roth Shaberman, PhD, and Brett D. Mahon, PhD, at C4 MedSolutions, LLC, a CHC Group company; funding was provided by Otsuka Pharmaceutical Commercialization, Inc. and H. Lundbeck A/S

\section{Acknowledgements}

The authors would like to thank Svetlana Ivanova, PhD, Otsuka Pharmaceutical Develop ment \& Commercialization, Inc., Rockville, MD, USA, for her contribution to the analysis and interpretation of data.

\section{References}

1 Heres S, Schmitz FS, Leucht S, Pajonk FG. The attitude of patients towards antipsychotic depot treatment. Int Clin Psychopharmacol 2007; 22: 275-82.

2 Patel MX, De Zoysa N, Bernadt M, David A. Depot and oral antipsychotics: patient preferences and attitudes are not the same thing. J Psychopharmacol 2009: 23: 789-96.
3 Kane J, Sanchez R, Perry P, Jin N, Johnson BR, Forbes RA, et al Aripiprazole intramuscular depot as maintenance treatment in patients with schizophrenia: a 52-week multicenter, randomized, double-blind, placebo-controlled study. J Clin Psych 2012; 73: 617-24.

4 Burris KD, Molski TF, Xu C, Ryan E, Tottori K, Kikuchi T, et al. Aripiprazole, a novel antipsychotic, is a high-affinity partial agonist at human dopamine D2 receptors. J Pharmacol Exp Ther 2002; 302: 381-9.

5 Croxtall JD. Aripiprazole: a review of its use in the management of schizophrenia in adults. CNS Drugs 2012; 26: 155-83.

6 Kay SR, Fiszbein A, Opler LA. The positive and negative syndrome scale (PANSS) for schizophrenia. Schizophr Bull 1987; 13: 261-76.

7 Guy W. ECDEU Assessment Manual for Psychopharmacology - Revised. US Department of Health Services, 1976.

8 Hough D, Gopal S, Vijapurkar U, Lim P, Morozova M, Eerdekens M. Paliperidone palmitate maintenance treatment in delaying the time-to-relapse in patients with schizophrenia: a randomized, doubleblind, placebo-controlled study. Schizophr Res 2010; 116: 107-17.

9 Mallikaarjun S, Kane JM, Bricmont P, McQuade R, Carson W, Sanchez R, et al. Pharmacokinetics, tolerability and safety of aripiprazole once-monthly in adult schizophrenia: an open-label, parallel-arm, multiple-dose study. Schizophr Res 2013; 150: 281-8.

10 American Psychiatric Association. Diagnostic and Statistical Manual of Mental Disorders (4th edn, revised) (DSM-IV-TR). APA, 2000.

11 Andreasen NC, Carpenter WT, Jr., Kane JM, Lasser RA, Marder SR, Weinberger DR. Remission in schizophrenia: proposed criteria and rationale for consensus. Am J Psychiatry 2005; 162: 441-9.

12 Simpson GM, Angus JW. A rating scale for extrapyramidal side effects. Acta Psychiatr Scand Suppl 1970; 212: 11-9.

13 Barnes TR. A rating scale for drug-induced akathisia. Br J Psychiatry 1989; 154: $672-6$.

14 Posner K, Brent D, Lucas C, Gould M, Stanley B, Brown G, et al. Columbia Suicide Severity Rating Scale. The Research Foundation for Mental Hygiene Inc, 2008 (http://cssrs.columbia.edu/docs/C-SSRS_1_14_09_Baseline.pdf).

15 Jensen MP, Chen C, Brugger AM. Interpretation of visual analog scale ratings and change scores: a reanalysis of two clinical trials of postoperative pain. J Pain 2003; 4: 407-14.

16 Kane JM, Eerdekens M, Lindenmayer JP, Keith SJ, Lesem M, Karcher K. Long-acting injectable risperidone: efficacy and safety of the first long-acting atypical antipsychotic. Am J Psychiatry 2003; 160: 1125-32.

17 Pigott TA, Carson WH, Saha AR, Torbeyns AF, Stock EG, Ingenito GG, et al Aripiprazole for the prevention of relapse in stabilized patients with chronic schizophrenia: a placebo-controlled 26-week study. J Clin Psychiatry 2003; 64: 1048-56.

18 Levine SZ, Rabinowitz J, Engel R, Etschel E, Leucht S. Extrapolation between measures of symptom severity and change: an examination of the PANSS and CGI. Schizophr Res 2008; 98: 318-22.

19 Kasper S, Lerman MN, McQuade RD, Saha A, Carson WH, Ali M, et al. Efficacy and safety of aripiprazole vs. haloperidol for long-term maintenance treatment following acute relapse of schizophrenia. Int J Neuropsychopharmacol 2003; 6: 325-37.

20 Hasan A, Falkai P, Wobrock T, Lieberman J, Glenthoj B, Gattaz WF, et al. World Federation of Societies of Biological Psychiatry (WFSBP) Guidelines for Biological Treatment of Schizophrenia, Part 2: Update 2012 on the long-term treatment of schizophrenia and management of antipsychotic-induced side effects. World J Biol Psychiatry 2013; 14: 2-44

21 Tiihonen J, Haukka J, Taylor M, Haddad PM, Patel MX, Korhonen P. A nationwide cohort study of oral and depot antipsychotics after first hospitalization for schizophrenia. Am J Psychiatry 2011; 168: 603-9.

22 Rosenheck RA, Krystal JH, Lew R, Barnett PG, Fiore L, Valley D, et al. Long-acting risperidone and oral antipsychotics in unstable schizophrenia. N Engl J Med. 2011; 364: 842-51.

23 Kirson NY, Weiden PJ, Yermakov S, Huang W, Samuelson T, Offord SJ, et al. Efficacy and effectiveness of depot versus oral antipsychotics in schizophrenia: synthesizing results across different research designs. J Clin Psychiatry 2013; 74: 568-75.

24 Kishimoto T, Robenzadeh A, Leucht C, Leucht S, Watanabe K, Mimura M, et al. Long-acting injectable vs oral antipsychotics for relapse prevention in schizophrenia: a meta-analysis of randomized trials. Schizophr Bull 2014; 40 192-213.
EXTRA 